\title{
Research and Advances of Silicate Plugging Agent in the Oilfields
}

\author{
Juan Zhao ${ }^{1,2^{*}}$, Jian Zhang1,2 \\ ${ }^{1}$ State Key Laboratory of Offshore Oil Exploitation, Beijing, China \\ ${ }^{2} \mathrm{CNOOC}$ Research Institute Co., Ltd., Beijing, China \\ Email: *zhaojuanupc@163.com
}

How to cite this paper: Zhao, J. and Zhang, J. (2019) Research and Advances of Silicate Plugging Agent in the Oilfields. Journal of Materials Science and Chemical Engineering, 7, 1-10.

https://doi.org/10.4236/msce.2019.79001

Received: July 30, 2019

Accepted: September 24, 2019

Published: September 27, 2019

Copyright (c) 2019 by author(s) and Scientific Research Publishing Inc. This work is licensed under the Creative Commons Attribution International License (CC BY 4.0).

http://creativecommons.org/licenses/by/4.0/

\begin{abstract}
The paper overviews the research and application of silicate plugging agent, according to the different mechanisms and application forms, the plugging agent is divided into silicate gel, silicate precipitation, silicate/polymer, silicate/surfactant, silicate gel/foam and so on. This paper chiefly introduces the conception, mechanism and development tendency of the different systems mentioned above. The development tendency manifests as fully utilize personal properties and cooperate with other plugging agents or technologies, including the study of reaction mechanism, combination of plugging agent, grasping water flood timing, developing deep profile control and water shutoff technology, combining with other measures (chemicals huff and puff), in order to play the role of such blocking agents, further enhance oil recovery.
\end{abstract}

\section{Keywords}

Silicate Plugging Agent, Silicate Gel, Silicate Precipitation, Silicate/Polymer, Silicate/Surfactant, Silicate Gel/Foam, Development Tendency

\section{Introduction}

Currently, most oil fields in China have entered the late stage of development, and profile control and water plugging has become an important technical measure in domestic and international high water-content oilfield to improve water flooding effect. Simultaneously more and more oil formation, higher and higher temperature, more and more reservoir water salinity. Research of temperature-resistance and salt-tolerance plugging agent becomes more and more important. Most of the existing relative temperature-resistance and salt-tolerance cross-linked polymer plugging agent is based on low-temperature gel, and it only applies to the following reservoirs: temperature is below $120^{\circ} \mathrm{C}$ and salinity is 
below $8 \times 10^{4} \mathrm{mg} \cdot \mathrm{L}^{-1}$.

We have used polymer pre-crosslinking swell particle and fibrous pre-crosslinking swell particle in high-temperature and high-salinity reservoirs [1] [2] [3] [4] [5], but the sealing ability is bad. May the problem above mentioned can be resolved by means of the developing the inorganic blocking agent. Silicate plugging agent has temperature-sensitive, salt-sensitive, Ca-Mg sensitive, and so on, so we can make full use of reservoir physical and chemical characteristics to profile control. Silicate plugging agent possesses many advantages such as low price, temperature tolerant, salt-tolerant, good injectivity, selective plugging, environment-friendly, non-biodegradation, and so on. In recent years, more and more the plugging agent based on silicate is applied in high-temperature and high-salinity reservoirs.

Profile control is a problem in high-temperature and high-salinity reservoirs [6], and silicate plugging agent was extensively applied in water plugging, profile control, inhibition gas coning, stability of reservoir rock and clay [7]-[12]. Silicate can be divided into many types in accordance with plugging mechanism. This paper summarized the application of silicate plugging agent in the oilfields.

\subsection{Silicate Gel}

Early in the 1920s, Hills [13] has recognized the silicate gel can be used to improve heterogeneity of formation, and Hurd [14] further studies of acid silica gel system. Silica gel is formed by the silicate solution added the activator (ammonium sulfate, $\mathrm{HCl}$, formaldehyde, etc.), and first it forms monomeric silicic acid, then forms multsiilicic acid through condensation polymerization, finally forms network structure. The jellous silicic acid can plug watering place and water producer, and the forming process follows as Figure 1.

Two silica gels can be prepared according to the adding sequence of activator, and one is acid silica gel, adding the silicate solution into activator, the other is alkalic silica gel, adding the activator into silicate solution. Its low cost allows economical treatment of 1.5 to $3 \mathrm{~m}$ radially around wellbore. It invades small formation pores and is stable at high temperatures. The drawback is short gel time.

WU Jia-Zhong [15] developed the system of fluosilicic acid-silicate, the mechanism of reaction ut infra. 1) The reaction of fluoride acid and formation brine: $\mathrm{H}_{2} \mathrm{SiO}_{6}+2 \mathrm{NaCl}=\mathrm{Na}_{2} \mathrm{SiF}_{6} \downarrow+2 \mathrm{HCl}, \mathrm{H}_{2} \mathrm{SiF}_{6}+\mathrm{CaCl}_{2}=\mathrm{CaSiF}_{6} \downarrow+2 \mathrm{HCl}$;

2) The reaction of silicate and fluoride acid:

$\mathrm{H}_{2} \mathrm{SiO}_{6}+\mathrm{Na}_{2} \mathrm{O} \cdot m \mathrm{SiO}_{2}+n \mathrm{H}_{2} \mathrm{O}=\mathrm{Na}_{2} \mathrm{SiF}_{6}+m \mathrm{SiO}_{2} \cdot(n+1) \mathrm{H}_{2} \mathrm{O} \downarrow$

3) The reaction of silicate and sodium fluosilicate:

$\left.2\left(\mathrm{Na}_{2} \mathrm{O} \cdot m \mathrm{miO}_{2}\right)+\mathrm{Na}_{2} \mathrm{SiF}_{6}=6 \mathrm{NaF}+(2 m+1) \mathrm{SiO}_{2} \downarrow ; 4\right)$ The gelation of $\mathrm{NaCl}$ and silicate. Silicate and sodium fluoride generate amorphous silicon dioxide, high activity, and increase the intensity of blocking agent. The advantages of the system are low cost, good profile control and sand consolidation ability. The dual effects of profile control and sand consolidation can be observed when it is used in water injection wells. 


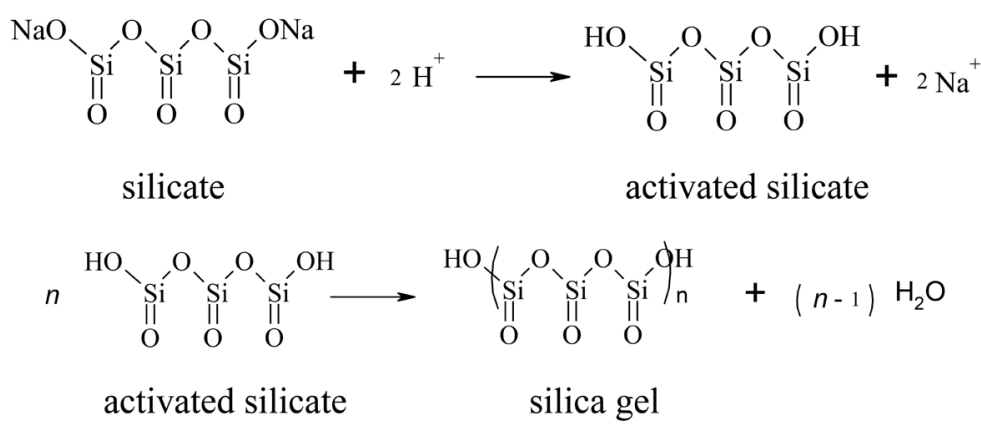

Figure 1. The forming process of silica gel.

LU Xiang-Qun [16] have recommended using two delay activators marked as YHJ-1 and YHJ-2, and they have been successfully used as blocking and diverting agents to treat injection and production wells in Henan Oilfield. Reservoirs in Tarim Basin, NW China, were geologically developed in marine environment with high temperature and high salinity. To address the problem in Tarim Basin [17], profile control agent with abio-gel coating (WJSTP) is developed by taking advantage of the multi-valence cations concentrated in both the formation and injection water and injects a compounded silicate to react with the cations to form abio-gel with the same density as water. The method was tested successfully in LN203 well in March 2006. The average injection pressure boosted, and injection profile obviously improved.

A. H. Kabir [18] proposed a simple system for use in sandstone formations is prepared by slowly adding a sodium silicate solution to a $15 \% \mathrm{HCl}$ acid solution and then pumped into the well. This solution solidifies in a few hours, depending on the temperature. U.S. Pat.5351757 [19] disclosed a method for emplacing a silicate gel to improve the sweep efficiency through controlling quantities of a silicate solution and either a gas or a gas and an organic acid are injected into a well to infiltrate and generate a controlled amount of a silicate gel of a controlled $\mathrm{SiO}_{2}$ concentration in the high-permeability thief zones, to reduce the permeability thereof. The Bashkir oilfield of Russia used gel precipitation and its advanced formula to treat injection well, alternating injecting silicate and slurry, then formed gel and precipitation in stream path, thereby decreased the permeability of high capacity channel.

A silicate system activated by urea-formaldehyde [20] was raised. The urea reacts with $\mathrm{OH}^{-}$in silicate solution, reducing the $\mathrm{pH}$ value of the system, and then the silicate ions generated silica gel by condensation polymerization, which is represented in Figure 2. Core test showed that the gel can reduce the core permeability by three orders of magnitude. We can avoid generating the calcium silicate, magnesium silicate by means of adding chelator (EDTA), and it does not affect the gel time and gel strength. Sodium silicate solution and urea solution are both alkaline, and it will not cause corrosion of equipment. The system is affected by the mass fraction of sodium silicate and urea, temperature, inorganic salts and other factors. 


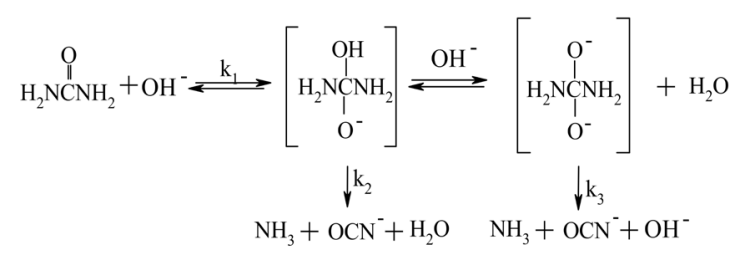

Figure 2. Reaction of urea and $\mathrm{OH}^{-}$.

\subsection{Silicate Precipitation}

It can generate precipitation when the silicate met calcium and magnesium ions in high temperature conditions, and reaction is shown in Figure 3. Two-fluid method can be used in the precipitation reaction for the purpose of blocking layers.

Silicate-calcium/magnesium chloride system is commonly used as silicate precipitation system, the working fluid easier entering into thief zone, so the system is usually used to block high permeable layer. Alternately injecting silicate and calcium/magnesium chloride into selective zone, isolated by clear water, then the two solutions mixed in the pore and yield the water insoluble precipitation:

$$
\begin{aligned}
& \mathrm{CaCl}_{2}+\mathrm{Na}_{2} \mathrm{O} \cdot m \mathrm{miO}_{2}=\mathrm{CaO} \cdot \mathrm{mSiO}_{2} \downarrow+2 \mathrm{NaCl} \\
& \mathrm{MgCl}_{2}+\mathrm{Na}_{2} \mathrm{O} \cdot \mathrm{mSiO}{ }_{2}=\mathrm{MgO} \cdot m \mathrm{miO}_{2} \downarrow+2 \mathrm{NaCl}
\end{aligned}
$$

The traditional silicate-calcium chloride system reacts quickly and play little role on the aim lay, alkali silicic acid gel has week strength, poor high-temperature-resistance, non-selectivity. On the base of tradition silicate system, PEI Lixia [21] developed the LS water blocking system, which is composed of calcium chloride and silicate as principal ingredient, complex, activator and LS as accessory ingredient. The complex can delayed gel time by controlling the concentration of $\mathrm{Ca}^{2+}$, because the $\mathrm{Ca}^{2+}$ can react with the complex follows as Figure 4 . The effect of LS is concealing the $\mathrm{Ca}^{2+}$ and enhancing the gel strength. The LS system does not only keep the outstanding characteristic of the former system, but also has advantage such as high-temperature resistance, salt resistance, strong intensity, dominant selectivity, controllable reaction time, non-corrosion, non-solid, deep blocking, etc.

U.S. patents 3,350,937 and 3,882,938 by Bernard [22] [23] and 3,805,893 by Sarem [24], both of Union, describe the use of alternate slugs of silicate and calcium chloride to improve sweep and mobility control in heterogeneous reservoirs. U.S. patent 4,304,301 by Sydansk [25] of Marathon claims the use of a caustic solution and magnesium chloride in sequential slugs. The chemicals mix in the reservoir to form a magnesium hydroxide precipitate that blocks pores and alters flow profiles in the reservoir. U.S. patents 2,747,670 and 3,342,262 by King and Fallgatter [26] [27] of Cities Services describe the use of alternate slugs of alkalis (sodium silicate) and salts of various metals (aluminum sulfate) with short spacer slugs sized to provide for multiple cyclic injection and reaction. The two reactant slugs contact each other in concentric regions of the formation. The formed precipitates deposit in the more permeable zones and achieve deeper penetration. 


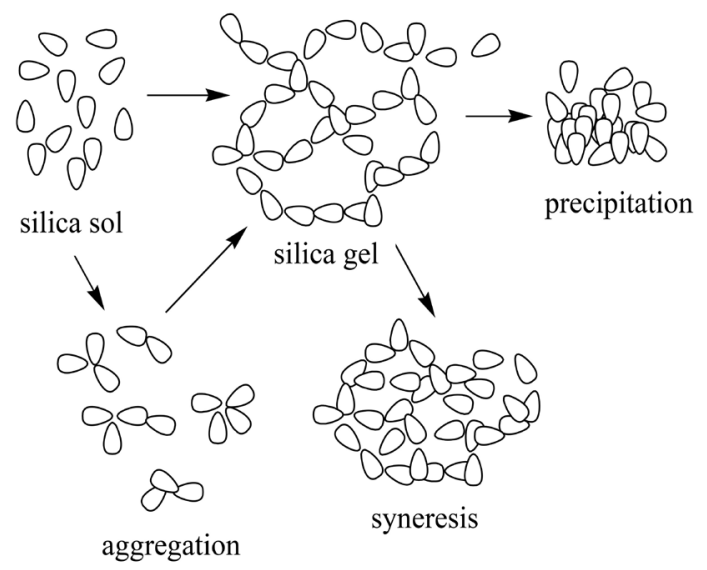

Figure 3. The role of calcium and magnesium ions on the sol.

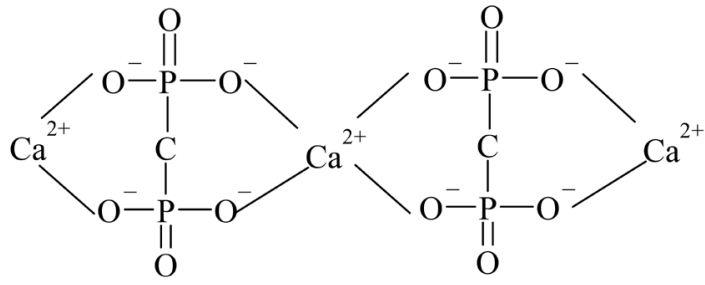

Figure 4. Reaction of $\mathrm{Ca}^{2+}$ and complex.

\subsection{Silicate/Polymer Multisystem}

In recent years, the system that adding the polymer solution into the silicate solution has new development in plugging the thief zone [28]. The multisystem has better sealing capacity, greater strength and longer gel time than single system. The polymer' network and silicate gel simultaneous proceed, and the network limit the move of the large silica gel, at the same time the silica gel increases the mobile resistance of network. This synergistic effect makes the plugging agent has good elasticity and high strength.

\subsection{Silicate/Surfactant Multisystem}

Highly conductive zones in subterranean formations are treated with aqueous fluids containing gel-forming amounts of water-soluble lignosulfonate and silicate [29]. With the increase of surfactant concentration, the viscosity of silica gel greatly improved and played a role in profile control. The lignosulfonate can reduce the interfacial tension and played a role in improving displacement efficiency. The multisystem enhanced not only the sweep efficiency but also the displacement efficiency. Suitable water-soluble lignosulfonates and silicates are commercially available as aqueous solutions or as powders.

In order to improve the corrosion of equipment and scaling of alkali, ZHONG Qiang [30] researched the multisystem of phosphorus silicate/surfactant/polymer. The results indicate that the phosphorus silicate adjuvant can improve the profile control ability of the flooding system and can enhance $35.9 \%$ of recovery efficiency. 


\subsection{Silicate Gel/Foam Multisystem}

Foamed gels have also demonstrated great potential as gas and liquid diverting fluids. Furthermore, foam systems can be injected into rock formations as an important means for $\mathrm{CO}_{2}$ and green gases recycling. A kind of silicate gel enhanced foam system used in the deep profile control of typical heterogeneous reservoir was proposed by ZHAO Ren-bao [31]. When the silicate concentration is very low, the system can generate acid silicate sol by decreasing $\mathrm{pH}$ value. The silicate sol can react with calcium carbonate, then produce $\mathrm{CO}_{2}$, increase the $\mathrm{pH}$ value of the system, and the calcium ions have accelerating effect. Under the action of the foam agent, gas is coated by the sodium silicate gel, then forming the gel foam system. This gel foam system has smaller diameter, more concentrated distribution, better stability than the gel foam based polymer. The application of the system can solve the environmental pollution, but also improve the effect of water injection and enhance oil recovery, so its economic and social benefits are very obvious. U.S. patent 2,402,588 by Anderson [32] of Essex Royalty Corp. and 3,285,338 by Boston [33] both of Mobil discuss the use of sodium silicate solutions containing from 1 to 15 weight percent $\mathrm{SiO}_{2}$. The silicate reacts with injected $\mathrm{CO}_{2}$ from an EOR miscible flood to form a gel at some distance in the reservoir. The $\mathrm{CO}_{2}$ dissolved in the water phase as carbonic acid $\left(\mathrm{H}_{2} \mathrm{CO}_{3}\right)$ acts as the gelling agent by neutralizing the alkalinity. Buffer slugs of natural gas or air may be used to isolate the silicate so that deeper penetration is achieved prior to gelation. Formation of gel zones then improves the sweep of the $\mathrm{CO}_{2}$ miscible flood.

\section{Development Tendency}

At present, the plugging agent has been divided into various series, but plugging agent with special functions is still a shortage. Making full use of the cheap silicate plugging agent not only reduces the production cost but also solves water problems and environmental pollution. According to China's exploitation characteristics of the reservoir and status of oil exploration, we put forward the following views:

1) Strengthen research the microscopic mechanism of silicate plugging agent. We should regard the physical-chemical effect, existing form and flow behavior when silicate gel in oil layer. Make full use of the properties such as temperature sensitive, salt sensitive, $\mathrm{Ca}-\mathrm{Mg}$ sensitive and so on, and generate precipitation in high temperature and salinity reservoirs. Put the silicate plugging agents of different application forms into the optimum formation.

We can also combine the plugging agents according to drawdown curve, and the strong agent can seal immediate vicinity of wellbore and the weak agent can seal the deep formation. Reasonable combination of blocking agent can take advantage of blocking agent and lower cost.

2) Develop the deep profile technology. As the advanced secondary depletion technology, deep profile technology plays an important role in high water cut oilfield. Research the advisable injection process, and bring the silicate into the deep 
formation. We can make use of microcapsules method and coat silicate through thin film, then the silicate can migrate into the deep formation. The technology will be used in the two-fluid method for profile control, dispersing one reaction solution and coating films, then spread to another reaction solution.

The plugging agent will become deformed when it passes the pore, so the film is liquid. We can use the method which prepared $\mathrm{W}_{1} / \mathrm{O} / \mathrm{W}_{2}$ multiple emulsions to generate the film. Multiple emulsions are developed as a $\mathrm{W}_{1} / \mathrm{O} / \mathrm{W}_{2}$ new system for water flooding reservoirs, and the silicate takes the action after running through two-layer coats, thereby delay release velocity of the agent. The reaction time can be controlled through adjusting the thickness and strength of coating. When the silicate migrates in the pore throat, the coating will be sheared thinner and thinner as shown in Figure 5.

3) Combine with other measures. For instance, the chemicals huff and puff technique combined with water shutoff in oil well. First inject different huff and puff agent such as high effective oil displacement agent, viscosity reducer, demulsifier, inhibiter, scale inhibitor and so on, and the huff and puff agent preferential access to high-permeability layers. Then inject plugging agent to oil well, and handle the huff and puff agent storage in high permeability layer. When put back on production, the water along the high permeability layers flows into the low permeability layer because of plugging agent, and the water will also bring the huff and puff agent into the low permeability layer follows as Figure 6.

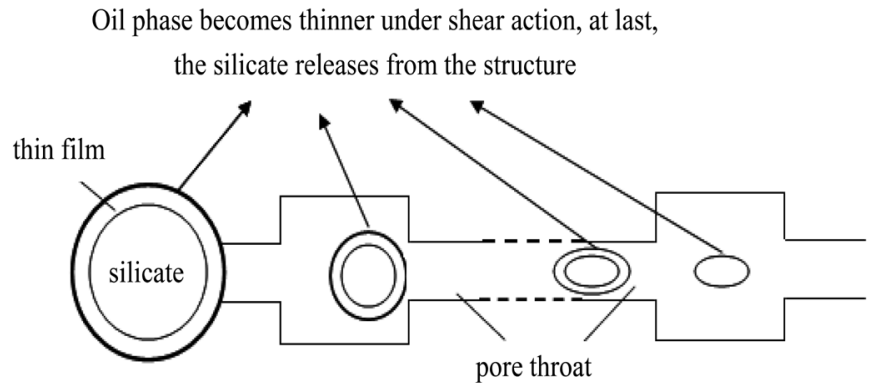

Figure 5. The release process of silicate.

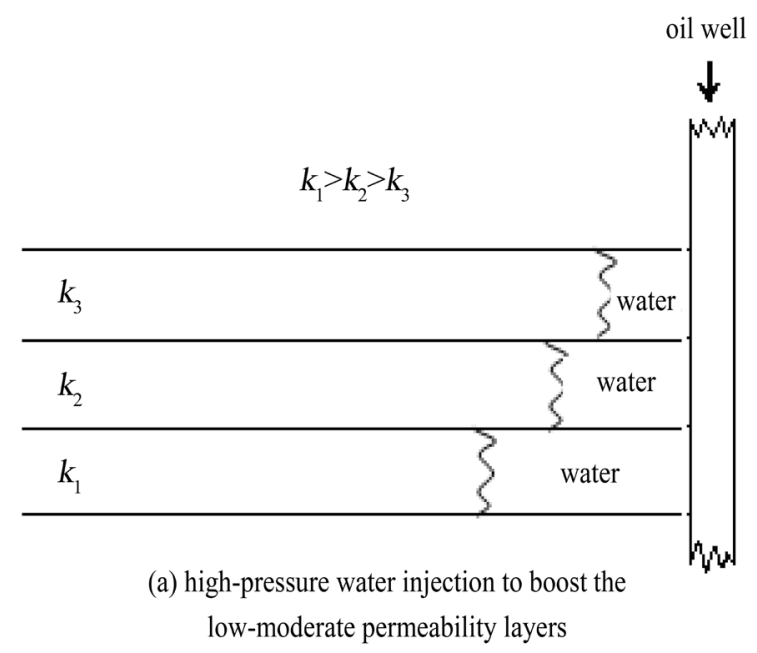



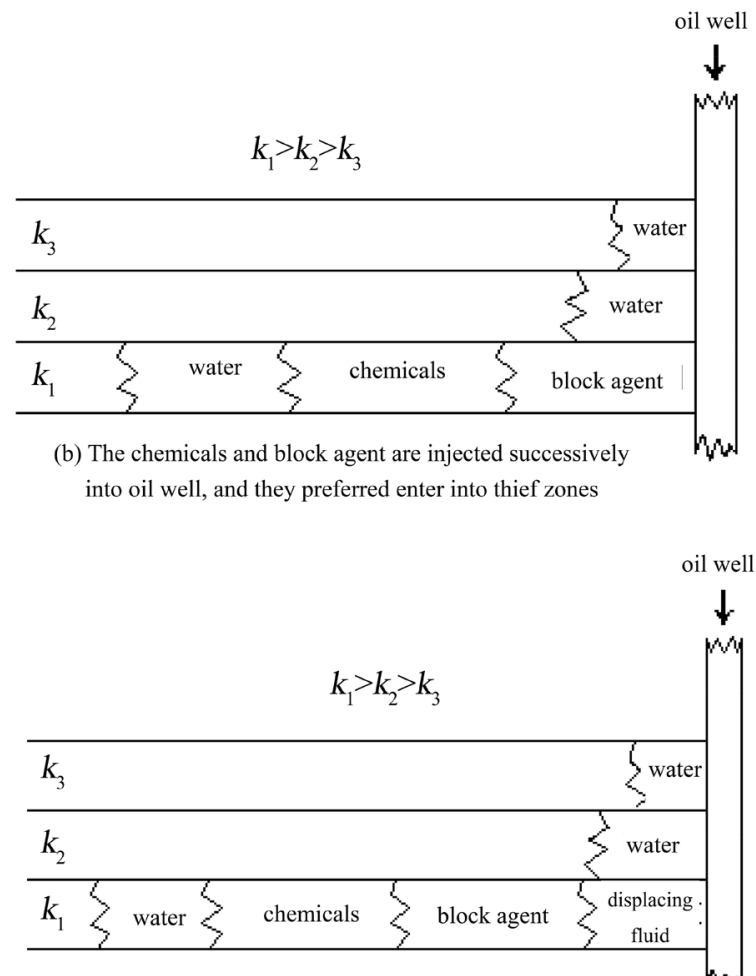

(c) The chemicals are displaced to $3 \mathrm{~m}$ away from the borehole by over-displacing fluid

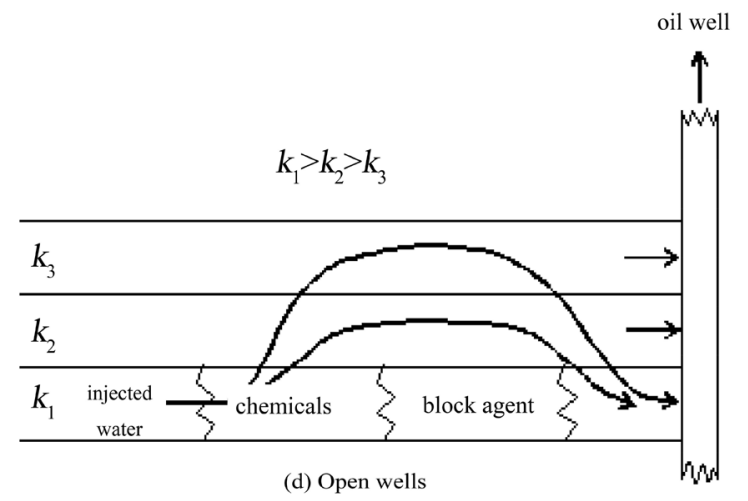

Figure 6. The huff and puff technique combined with water shutoff in oil well.

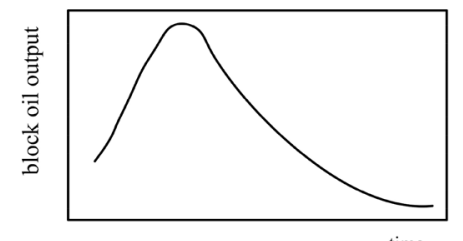

(a) without profile control

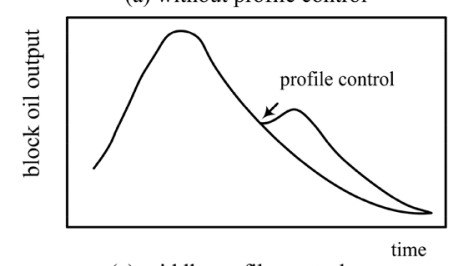

(c) middle profile control

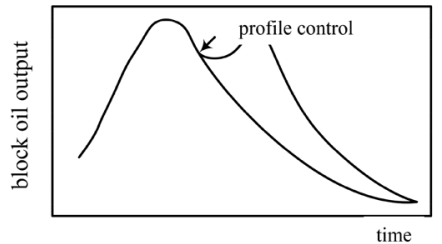

(b) early profile control

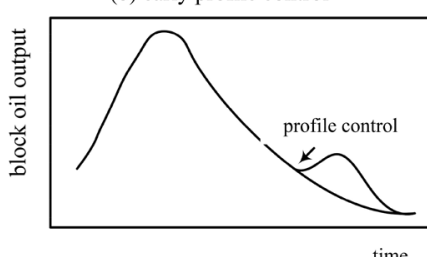

(d) late profile control

Figure 7. Effect of profile control time on block oil production. 
4) Grasp injection time. The blocking agents have different ability of increasing oil at different injection time. Some scholars proposed that when the oil yield started to decline, it is the best time to injecting blocking agent follows as Figure 7.

\section{Conflicts of Interest}

The authors declare no conflicts of interest regarding the publication of this paper.

\section{References}

[1] Lu, X.-G., Wang, W., Su, Y.-C., et al. (2005) An Experimental Study on Performance Properties of Swellable Granular Precrosslinked Polymer. Oilfield Chemistry, 22, 324-327.

[2] Castelijins, H.J., Pel, L., Huinink, H.P. and Jose Zitha, P.L. (2006) Mass Transfer and Gelation in Sandstone Cores of a Novel Water Shutoff Chemical. SPE99684-MS. https://doi.org/10.2118/99684-MS

[3] Prado, M., Palencia, J., Reyna, M., et al. (2005) Two Different Water Shutoff Applications in a Poorly Consolidated Sandstone Reservoir with Strong Waterdrive. SPE93060-MS. https://doi.org/10.2118/93060-MS

[4] Yuan, M., Yin, W.-J. (2003) Industrial Application in Large-Scale Multiple Water Plugging and Profiling Technology. Petroleum Exploration and Development, 30, 88-90.

[5] Cao, J.-K., Yang, S.-Z., Zhang, H.-Q., et al. (2002) A Research for Water Shutoff in the Bottom Water Reservoir. Petroleum Exploration and Development, 29, 80-81+88.

[6] Han, D.-K. (1995) An Approach to Deep Development of High Water-Cut Oil Field to Improve Oil Recovery. Petroleum Exploration and Development, 22, 7-55.

[7] Smith, L.R., Fast, C.R. and Wagner, O.R. (1969) Development and Field Testing of Large Volume Remedial Treatments for Gross Water Channeling. Journal of Petroleum Technology, 21, 1015-1025. https://doi.org/10.2118/2217-PA

[8] Hering, G.D., Milloway, J.T. and Wilson, W.N. (1984) Selective Gas Shut-Off Using Sodium Silicate in the Prudoe Bay Field, AK. SPE12473, Bakersfield, CA.

[9] Vinot, B., Schechter, R.S. and Lake, L.W. (1989) Formation on Water/Soluble Silicate Gels by the Hydrolysis of a Diester of Dicarboxylic Acid Solublized as Microemulsions. SPE Reservoir Engineering, 4, 391. https://doi.org/10.2118/14236-PA

[10] Islam, M.R. and Farouq Ali, S.M. (1993) Use of Silica Gel for Improving Waterflooding Performance of Bottom-Water Reservoir. Journal of Petroleum Science and Engineering, 8, 303-313. https://doi.org/10.1016/0920-4105(93)90007-2

[11] Creel, P. and Crook, R. (1997) Gels, Monomer Solutions Fix Pinhole Casing Leaks. Oil \& Gas Journal, 13, 44-46.

[12] Boreng, R. and Svendsen, O.B. (1997) Successful Water Shut-Off. A Case Study from the Strafjord Field. SPE37466, Oklahoma, OK. https://doi.org/10.2118/37466-MS

[13] Mills, R.V.A. (1922) Process of Excluding Water from Oil and Gas Wells. US Patent No. 1421706.

[14] Hurd, C.B. (1938) Theories for Mechanism of the Setting of Silica Acid Gels. Chemical Reviews, 22, 403-422. https://doi.org/10.1021/cr60073a001

[15] Wu, J.-Z., Wang, T., Li, K.-H., et al. (2001) Study on Fluorsilicic Acid-Water Glass as Profile Control Agent. Science \& Technology in Chemical Industry, 9, 24-26. 
[16] Lu, X.-Q., Liu, Z.-Q., Jia, L.-Y., et al. (2004) Preparation of Delayed Gelating Silicic Acid Sol as Water Control Agent. Oilfield Chemistry, 21, 33-35.

[17] Tang, X.-F., Liu, Y.-Z., Chang, Z.-L., et al. (2004) Profile Modification Agent with Abio-Gel Coating for High-Temperature and High-Salinity Reservoir. Petroleum $E_{X}-$ ploration and Development, 31, 92-94.

[18] Kabir, A.H. (2001) Chemical Water \& Gas Shutoff Technology-An Overview. SPE72119-MS. https://doi.org/10.2118/72119-MS

[19] Chou, S. and Bae, J. (1994) Method for Silica Gel Emplacement for Enhanced Oil Recovery. US Patent No. 5351757.

[20] Nasar-El-Din, H.A., Bitar, G.E., Bou-Khamsin, F.I., Al-Mulhim, A.K. and Hsu, J. (1998) Field Application of Gelling Polymers in Saudi Arabia. SPE 39615, Tulsa, Oklahema, OK. https://doi.org/10.2118/39615-MS

[21] Pei, L.-X. (2001) Study and Application of New Inorganic Gel. Southwest Petroleum Institute, Nanchong.

[22] Bernard, G.C. and California L.M. (1970) Method for Water Flooding Heterogeneous Petroleum Reservoirs. US Patent No. 3530937.

[23] Schmidt, A.W. and Treeman, R.B. (1975) Fluid-Powered Crimping Press. US Patent No. 3883938.

[24] Sarem, A.M. and Linda, Y. (1974) Mobility-Controlled Caustic Flood. US Patent No. 3805893.

[25] Sydansk, R.D. and Colo, L. (1981) Process for Improving Conformance and Flow Profiles in a Subterranean Formation. US Patent No. 4304301.

[26] King, J.A. and Fallgatter, W.S. (1956) Method of Increasing Oil Recovery. US Patent No. 2747670.

[27] King, J.A. and Fallgatter, W.S. (1967) Method of Increasing Oil Recovery. US Patent No. 3342262.

[28] Sandiford, B.B. (1976) Placentia Calif. Selectively Controlling the Flow of Fluids through Subterranean Formations. US Patent No. 4009755.

[29] Lawrence, D.D. and Felber, B.J. (1981) Formation Treatment with Silicate Activated Lignosulfonate Gel. US Patent No. 4257813.

[30] Zhong, Q., Zang, W. and Lu, X.-G. (2008) Performance Evaluation of Phosphorus Silicate and Polymer Combination System. Petroleum Geology and Recovery Efficiency, 15, 63-65.

[31] Zhao, R.-B., Yue, X.-A., Xu, R.-X., et al. (2005) Properties of Water-Glass-Gel Enhanced Foam System. Journal of Jilin University (Engineering and Technology Edition), 35, 572-575.

[32] Anderson, K.H. (1946) Method of Oil Recovery. US Patent No. 2402588.

[33] Boston, W.G. (1963) Method of Oil Recovery. US Patent No. 3285338. 